\title{
Un análisis de las oportunidades laborales de los excombatientes desde la perspectiva del sector empresarial*
}

\section{Analysis of job opportunities for ex-combatants from a business sector perspective}

\author{
Giovanny Sandoval-Paucar ${ }^{1}$ \\ Docente de Universidad Antonio Nariño, Bogotá, Colombia \\ giovanny.sandoval@correounivalle.edu.co \\ https://orcid.org/0000-0003-2139-0450 \\ Alexandra Arango-Ospina ${ }^{2}$ \\ Docente de Universidad Antonio Nariño, Palmira, Colombia \\ alexarango@uan.edu.co \\ https://orcid.org/0000-0002-7427-005X \\ Patricia Rodríguez-Vélez ${ }^{3}$ \\ Docente de la Universidad Antonio Nariño, Palmira, Colombia \\ patricrodriguez@uan.edu.co \\ https://orcid.org/0000-0001-6109-3659 \\ Millerlandy Santana-Oviedo 4 \\ Docente de la Universidad Antonio Nariño, Palmira, Colombia \\ millersa@uan.edu.co \\ https://orcid.org/0000-0001-6840-1781
}

Recibido: 15-01-19

Aprobado: 27-08-19

\footnotetext{
* Este artículo es el resultado del proyecto de investigación 2016232-3 J5 "Análisis del posconflicto desde los aspectos que deben considerarse en la vinculación de los reinsertados al mercado laboral, específicamente en las Mipymes del nororiente del Cauca y suroccidente del Valle del Cauca", realizado por los autores entre 2016-2018, con el financiamiento de la Vicerrectoría de Ciencia, Tecnología e Innovación (VCTI) de la Universidad Antonio Nariño.

1 Maestría en Economía Aplicada.

2 Maestría en Administración.

3 Maestría en Gerencia Financiera y Tributaria.

4 Maestría en Educación.
} 


\section{Resumen}

El artículo analiza las percepciones de los empresarios en las ciudades de Palmira, Florida, Candelaria y Pradera (Colombia) respecto a la contratación laboral de excombatientes en sus empresas. La metodología empleada es un muestreo estratificado y un modelo logit multinomial para examinar las apreciaciones de los empresarios. Encontramos que las actitudes del sector empresarial están polarizadas respecto a la vinculación laboral de excombatientes. A su vez, las percepciones respecto al proceso de paz presentan un efecto negativo sobre la decisión de contratar excombatientes, en cambio, las percepciones sobre las políticas de incentivos del gobierno muestran un efecto positivo sobre esta decisión.

Palabras claves: excombatientes; reintegración; proceso de paz; políticas económicas; logit multinomial.

Clasificación JEL: J23, J71, J78.

\section{Abstract}

The following article analyzes the perceptions of entrepreneurs in the cities of Palmira, Florida, Candelaria and Pradera (Colombia) regarding the hiring of ex-combatants in their companies. The methodology used is a stratified sampling and a multinomial logit model to examine the appreciations of entrepreneurs. As a result, it is obtained that the attitudes of the business sector are polarized in terms of the employment of ex-combatants. Similarly, perceptions regarding the peace process have a negative effect on the decision when hiring ex-combatants, while perceptions on government incentive policies show a positive effect on this decision.

Keywords: Ex-Combatants; Reintegration; Peace Process; Economic Policies; Multinomial Logit.

¿Cómo citar este artículo? / How to quote this article?

Sandoval-Paucar, G., Arango-Ospina, A., Rodríguez-Vélez, P. y Santana-Oviedo, M. (2020). Un análisis de las oportunidades laborales de los excombatientes desde la perspectiva del sector empresarial. Sociedad y economía, (39), 134-154. https://10.25100/sye.voi39.7378 


\section{Introducción}

La sociedad colombiana se encuentra en un periodo de postacuerdo, después de la firma del acuerdo de paz entre el gobierno y las FARC. Durante el conflicto armado, Colombia padeció múltiples fenómenos sociales que tuvieron fuertes impactos en las dinámicas de convivencia, en la vida, la integridad, el desarrollo de los ciudadanos, los derechos sociales, la degradación del tejido social, los millones de víctimas y miles de victimarios, la economía, el desarrollo económico y en la sociedad en general. Gracias al reciente acuerdo de paz, los miembros de los Grupos Armados Ilegales (GAI) tienen la posibilidad de iniciar una nueva vida, vinculándose a la economía, ya sea como empresarios o empleados. No obstante, la construcción de un ciudadano independiente vinculado a legalidad de forma sostenible, que contribuya a la paz, a la seguridad y a la sociedad en general, tiene varios obstáculos que se deben superar (Iglesias, 2017). Por lo tanto, la etapa de postacuerdo en Colombia tiene como eje central el proceso de Desarme, Desmovilización y Reintegración (DDR) de los miembros de estos grupos.

La Agencia para la Reincorporación y la Normalización (ARN), durante los últimos 14 años, ha venido trabajando en la implementación de la Política de Reintegración Social y Económica (PRSE), que se encuentra inmersa en el Programa de Desarme, Desmovilización y Reintegración (Iglesias, 2017). Este programa busca mitigar, en parte, las consecuencias que ha dejado la violencia del conflicto armado. Los miembros reintegrados de los GAI tendrán el acompañamiento de la ARN a través de la ruta de reintegración. Durante esta ruta, los excombatientes y su grupo familiar reciben, por parte de la ARN, servicios de seguridad, salud, atención psicosocial, educación y formación de capacidades que facilitan su inserción económica tanto de empleado como de empresario, logrando disfrutar de sus derechos económicos y, por ende, desarrollar su carrera laboral o su proyecto de vida productivo.

La vinculación laboral de un individuo en una organización empresarial está condicionada, en parte, por el cumplimiento del perfil y las competencias solicitadas por la empresa. Adicionalmente, el postulante debe cumplir con ciertos rasgos que lo certifiquen como un empleado idóneo para el cargo. En el caso de los excombatientes, su pasado como miembros de un GAI, los convierte en candidatos con un rasgo que los desacredita y hace que la empresa tenga una percepción negativa. La teoría económica de la demanda laboral indica que los trabajadores con características diferenciadoras negativas pueden ser discriminados o excluidos del mercado laboral (Ehrenberg y Smith, 2012). En esta posible situación, radica la importancia del programa Desarme, Desmovilización y Reintegración (DDR) en la etapa de postacuerdo, de tal forma que los excombatientes logren una inserción económica y disfruten de sus derechos económicos como ciudadanos.

La participación del sector empresarial en la construcción de la paz y, especialmente, en el apoyo a los procesos de reintegración económica de los excombatientes está condicionada a las percepciones de los empresarios en relación a las expectativas, riesgos y oportunidades sobre los retos que implica hacer y construir la paz (CCB, 2015). De ahí la importancia de los procesos de DDR donde el rol del sector empresarial es fundamental para la reintegración económica de los excombatientes: las empresas pueden contribuir en la generación de oportunidades de empleo y el fortalecimiento empresarial. Estas son las dos grandes vías que tiene el sector empresarial para aportar en la construcción de una paz duradera en Colombia (CCB, 2015).

El objetivo de este trabajo es analizar las percepciones de los empresarios sobre la vinculación laboral de los excombatientes en las ciudades de Palmira, Florida, Candelaria y Pradera (Valle del Cauca, Colombia). El análisis empírico de este trabajo se centra en una encuesta a una muestra de 123 empresarios del sector privado. Para ello se busca, en primer lugar, caracterizar las principales variables de la encuesta, a través de una segmentación de estas, de acuerdo a la homogeneidad y características de respuesta. En segundo lugar, estimar la posibilidad de vinculación laboral de un excombatiente a través 
de un modelo logit multinomial. Por último, analizar el efecto de las percepciones de los empresarios sobre el proceso de paz y las políticas públicas de incentivos a la demanda laboral, sobre los resultados del modelo estimado.

Los resultados evidencian la polarización que está viviendo la sociedad colombiana respecto a este hecho histórico. Los empresarios encuestados están polarizados frente a la decisión de contratar a excombatientes en su planta de personal. Por otra parte, encontramos que las percepciones de los empresarios respecto al proceso de paz pueden afectar de forma negativa la decisión de contratación de los excombatientes. No obstante, las políticas de incentivos del gobierno pueden generar un efecto positivo sobre las decisiones de contratación de estos.

El documento está organizado en seis secciones además de esta introducción. En la primera sección, se discute el concepto de Reintegración. La segunda sección hace un recuento breve de la literatura acerca de la Reintegración. La metodología econométrica se describe en la tercera parte. En la cuarta sección, se exponen las fuentes de información y la forma como se obtuvieron. La sección cinco resume los resultados empíricos y, la última parte, expone las conclusiones e implicaciones de la investigación.

\section{Definición de reintegración}

De acuerdo a Nilsson (2005) las definiciones más representativas están agrupadas en dos categorías: la categoría práctica o profesional empleada por Organizaciones No Gubernamentales (ONG), nacionales e internacionales, y organismos internacionales como la ONU. En contraste, la categoría teórica es aquella utilizada por la literatura académica.

La mayoría de las definiciones prácticas tienen como grupo objetivo a los excombatientes, su familia y otros grupos afectados por la guerra. Se enfocan en la reintegración económica, política y social de los individuos. Por último, estas definiciones generalmente establecen métodos, programas y proyectos que se deben realizar para lograr un proceso de reintegración efectivo (Nilsson, 2005). En esta categoría se encuentran los trabajos de International Crisis Group (2003), ONU (1999) y Watteville (2001).

Por otro lado, las definiciones teóricas establecen como grupo objetivo a los excombatientes y sus familias, excluyendo a otros grupos afectados por la guerra. Se orientan en la reintegración económica, política y social de los excombatientes en la vida civil. En contraste, las definiciones prácticas no definen un método o programa para implementar la reintegración. Una corriente contemporánea de autores, según Torjesen (2013), De Vries y Wiegink (2011); Munive y Jakobsen (2012); Podder (2012); Bowd y Özerdem (2013); y Özerdem (2012).

\subsection{Perspectiva de económica política}

Torjesen (2013) argumenta que la mayoría de la literatura académica que discute la reintegración se enfoca en diseñar marcos de evaluación de los programas de DDR. A su vez, Torjesen (2013) sostiene que el trabajo de Berdal y Zaum (2013) provee un enfoque particularmente útil para estudiar los procesos de reintegración a través de la Economía Política. Berdal y Zaum (2013) definen un enfoque de economía política en situaciones de posconflicto basado en las relaciones de poder. La guerra establece nuevos órdenes sociales a través de redes e instituciones formales e informales, lo cual determina la actividad de los individuos en la esfera económica, social y política del posconflicto. El marco de Berdal y Zaum (2013) identifica las características más significativas del posconflicto, lo cual permite priorizar las variables más importantes, desde el punto de vista económico, para el estudio de la reintegración.

\section{Revisión de literatura}

Existe una vasta literatura sobre la reintegración económica y su relación con la demanda laboral de los empresarios, que sobrepasa los objetivos de este trabajo. Por lo tanto, este artículo intenta sintetizar los trabajos más representativos de las diferentes corrientes de pensamiento. 


\subsection{Literatura sobre la reintegración en Colombia}

Los trabajos más representativos del posconflicto colombiano, desde el punto de vista de la reintegración, se revisan brevemente a continuación. Porch y Rasmussen (2008) muestran que el proceso de desarme, la desmovilización y la reinserción (DDR), de los excombatientes en Colombia, simplemente es un mecanismo de transición y no un mecanismo para terminar con la violencia en el país. Theidon y Betancourt (2006) sostienen que una reintegración exitosa en Colombia requiere fusionar a los programas de DDR con medidas de justicia transicional y un análisis de género. De igual modo, Denissen (2010) afirma que una reintegración exitosa en Colombia depende de los siguientes factores: la estabilidad en los medios de subsistencia, un enfoque personalizado para la reintegración de los excombatientes, la prevención de la reincidencia en actividades ilegales, la participación de la comunidad y una implementación descentralizada de las políticas gubernamentales de reintegración. Igualmente, López, Andreouli y Howarth (2015) identifican el papel relevante del contexto social (comunidad) en los procesos de reintegración, la inclusión social y la construcción de nuevas identidades. Kaplan y Nussio (2015) encuentran que la reintegración social de los excombatientes en comunidades muy participativas tiende a requerir un menor tiempo de adaptación y sienten una menor necesidad de establecerse con sus antiguos compañeros de guerra. Mientras tanto, Oppenheim y Söderström (2018) encuentran evidencia de que la implementación de un programa de DDR (independiente de los resultados) tiene un fuerte impacto en la satisfacción de los excombatientes, lo cual sugiere que tanto la entrega de los beneficios como la forma de entrega de estos, son importantes para los excombatientes.

\subsection{Participación del sector privado en el posconflicto}

En cuanto a los autores más representativos que estudian las percepciones de los empresarios y su participación en la etapa de posconflicto,
Velasco (2006) estudia las percepciones de los empresarios de las principales ciudades de Colombia, mostrando que existen problemas para concretar la participación del sector empresarial en los procesos de reintegración, especialmente, los problemas institucionales y los relacionados con el proceso de reinserción. A su vez, Rettberg (2013) muestra cómo la promoción del activismo del sector empresarial en favor de la paz depende significativamente de los costos percibidos del conflicto y los beneficios esperados de la paz. También encuentra que las percepciones y el comportamiento del sector empresarial cambian, a través del tiempo, por los diferentes intentos de paz. Hinestroza, Santamaría y Rubio (2016) muestran que las actitudes de los empresarios en relación a la vinculación laboral de los desmovilizados, no son del todo positivas.

Por otra parte, CCB (2015) examina las percepciones del sector empresarial, la sociedad civil y las autoridades locales respecto a la construcción de la paz en Colombia, destacando la importancia de la creación de una agenda propia del sector empresarial, que direccione la participación del sector. A su vez, la CCB y FiP (2015) elaboran una guía para que el sector empresarial participe en la construcción de la paz, a través de la vinculación laboral de excombatientes en el proceso de reintegración. Igualmente, Guáqueta y Orsini (2007) realizan un informe donde compilan las lecciones y experiencias de la participación del sector empresarial en la incorporación laboral de los excombatientes, concluyendo que el concurso del sector empresarial es indispensable en la vinculación productiva de los desmovilizados en la estructura económica del país. Guáqueta (2006) examina la participación del sector empresarial en la construcción de la paz y la prevención de conflictos a través de la documentación de las mejores prácticas que han desarrollado los empresarios colombianos.

\section{Datos y Metodología}

\subsection{Muestra y Encuesta}

Para cumplir con el objetivo de la presente investigación, solo se considerarán las Micro, 
Pequeñas y Medianas Empresas (MIPYME) ubicadas en las ciudades de Palmira, Candelaria, Florida y Pradera del departamento del Valle del Cauca, en Colombia. Se utilizó el informe de composición empresarial por actividad económica de 2016, emitido por la Cámara de Comercio de Palmira, con una muestra de 123 empresas de las ciudades mencionadas.

Para el análisis, se utilizó una encuesta con preguntas estructurales, realizada directamente a los propietarios, gerentes generales y personal con puestos de alta gerencia que tienen el poder de tomar decisiones en la contratación y selección de personal. Se consideraron dos lugares para las encuestas: la dirección de la empresa y las instalaciones de la Universidad Antonio Nariño, la sede de Palmira. A continuación, se relaciona la distribución de las encuestas según la actividad económica: 49, sector comercial; 37, sector servicios (consultoría e inmobiliario); 15 , sectores industriales; 8 , sector transporte; 6 , sectores agropecuarios; 4 , sector construcción y, finalmente, 2 , sectores financieros.

\subsection{Metodología econométrica}

En este documento se emplea un modelo logit multinomial para estimar la probabilidad de vincular a un excombatiente.

La formulación de un modelo Logit Multinomial se representa a través de la siguiente ecuación:

$$
\operatorname{Pr}\left(Y_{i}=j\right)=P_{i j}=\frac{e^{\beta^{\prime}{ }_{j} X_{i}}}{\sum_{k=1}^{m} e^{\beta^{\prime}{ }_{j} X_{i}}},
$$

Siguiendo a Katchova (2013), la probabilidad de que el empresario $i$ seleccione la alternativa $j$ es:

$$
p_{i j}=p\left(y_{i}=j\right)=\frac{\exp \left(w_{i}^{\prime} \gamma_{j}\right)}{\sum_{k=1}^{m} \exp \left(w_{i}^{\prime} \gamma_{k}\right)},
$$

donde $j=$ indeciso, no y sí.

El efecto marginal de un aumento de un regresor sobre la probabilidad de seleccionar una alternativa $j$ es:

$$
\partial p_{i j} / \partial w_{i}=p_{i j}\left(\gamma_{j}-\bar{\gamma}_{i}\right)
$$

Por otra parte, el odds ratio mide la probabilidad de elegir $Y=j$ en lugar de $Y=0$ y viene dado mediante

$$
p_{i j} / w_{i k}=\exp \left(\boldsymbol{w}_{i}^{\prime}\left(\gamma_{j}-\gamma_{\mathrm{k}}\right)\right.
$$

Con base en las características de los empresarios, las características de las empresas y las percepciones de los empresarios respecto al proceso de paz y las políticas de incentivos del gobierno, se estiman los siguientes modelos:

\section{i. Modelo Base:}

(5) $\beta_{j}^{\prime} X_{i}=\beta_{o} x_{i}+\beta 1$ Edad $_{i}+\beta_{2}$ Sexo $_{i}+\beta_{3}$ Educación $_{i}+\beta_{4}$ Cargo $_{i}+\beta_{5}$ Antigüedad Laboral $_{i}+\beta_{6}$ Experiencias en quiebras ${ }_{i}+\beta_{7}$ Número de empleados $+\beta_{8}$ sector económico $_{i}$, 
Giovanny Sandoval-Paucar • Alexandra Arango-Ospina • Patricia Rodríguez-Vélez • Millerlandy Santana-Oviedo

\section{ii. Modelo Base Reducido:}

$\beta_{j}^{\prime} \mathrm{X}_{i}=\beta_{0} x_{i}+\beta 1$ Edad $_{i}+\beta_{2}$ Sexo $_{i}+\beta_{3}$ Educación $_{i}+\beta_{4}$ Antigüedad Laboral $_{i}+\beta_{5}$ Número de empleados $_{i}+$ $\beta_{6}$ sector económico, , (6)

\section{iii. Modelo Percepciones del Proceso de Paz}

$$
\beta_{j}^{\prime} \mathrm{X}_{i}=\beta_{0} x_{i}+\beta_{1} x_{1 i}+\beta_{2} x_{2 i}+\beta_{3} x_{3 i}+\beta_{4} x_{4 i}+\beta_{5} x_{5 i},(7)
$$

donde $X_{1 i}$ es ¿Está usted de acuerdo con lo firmado entre el gobierno nacional y las FARC EP?; $X_{2 i}$ es ¿Por qué está de acuerdo con lo firmado entre el gobierno nacional y las FARC EP?; $X_{3 i}$ es ¿Por qué está en desacuerdo con el proceso con las FARC?; $X_{4 i}$ es ¿Usted conoce algún programa de reintegración del Gobierno Nacional para excombatientes?; y $X_{5 i}$ es ¿Cuál es el principal desafío del posconflicto?

\section{iv. Modelo Base Reducido y Percepciones del Proceso de Paz}

$$
\beta_{j}^{\prime} \mathrm{X}_{i}=\beta_{0} x_{i}+\beta_{1} x_{1 i}+\beta_{2} x_{2 i}+\beta_{3} x_{3 i}+\beta_{4} x_{4 i}+\beta_{5} x_{5 i}, \beta_{6} x_{6 i}+\beta_{7} x_{7 i}+\beta_{8} x_{8 i}+\beta_{9} x_{9 i}+\beta_{10} x_{10 i}+\beta_{11} x_{11 i} \text {, (8) }
$$

Este modelo busca estimar la injerencia de las siguientes variables sobre la decisión de contratación de los empleadores, donde $X_{1 i}$ es Edad; $X_{2 i}$, Sexo; $X_{3 i}$ es Nivel de Educación; $X_{4 i}$ es Antigüedad Laboral; $X_{5 i}$ es Número de Empleados; $X_{6 i}$ es Sector Económico; $X_{7 i}$ es ¿Está usted de acuerdo con lo firmado entre el gobierno nacional y las FARC EP?; $X_{8 i}$ es ¿Por qué está de acuerdo con lo firmado entre el gobierno nacional y las FARC EP?; $X_{9 i}$ es ¿Por qué está en desacuerdo con el proceso con las FARC?; $X_{10 i}$ es ¿Usted conoce algún programa de reintegración del Gobierno Nacional para excombatientes?; y $X_{\mu i}$ es ¿Cuál es el principal desafío del posconflicto?

\section{v. Modelo Percepciones de las Políticas de Incentivos}

$$
\beta_{j}^{\prime} X_{i}=\beta_{0} x_{i}+\beta_{1} x_{1 i}+\beta_{2} x_{2 i}+\beta_{3} x_{3 i}+\beta_{4} x_{4 i}+\beta_{5} x_{5 i}, \beta_{6} x_{6 i} \text {, (9) }
$$

donde $X_{1 i}$ es Apoyo para la comercialización de sus productos; $X_{2 i}$ es Acceso a tecnología a menor costo; $X_{3 i}$ es Mayor reconocimiento para su empresa; $X_{4 i}$ es beneficios para licitaciones y concursos; $X_{5 i}$ es Alivios fiscales; y $X_{6 i}$ es Que una parte del salario de los excombatientes lo pague un tercero.

vi. Modelo Base Reducido y Percepciones de las Políticas de Incentivos

$\beta_{j}^{\prime} \mathrm{x}_{i}=\beta_{0} x_{i}+\beta_{1} x_{1 i}+\beta_{2} x_{2 i}+\beta_{3} x_{3 i}+\beta_{4} x_{4 i}+\beta_{5} x_{5 i}, \beta_{6} x_{6 i}+\beta_{7} x_{7 i}+\beta_{8} x_{8 i}+\beta_{9} x_{9 i}+\beta_{10} x_{10 i}+\beta_{11} x_{11 i}+\beta_{12} x_{12 i},(10)$

Este modelo examina el impacto de los siguientes beneficios en la decisión empresarial de contratar excombatientes, donde $X_{1 i}$ es Edad; $X_{2 i}$ es Sexo; $X_{3 i}$ es Nivel de Educación; $X_{4 i}$ es Antigüedad Laboral; $X_{5 i}$ es Número de Empleados; $X_{6 i}$ Sector Económico; $X_{7 i}$ es Apoyo para la comercialización de sus productos; $X_{8 i}$ es Acceso a tecnología a menor costo; $X_{9 i}$ es Mayor reconocimiento para su empresa; $X_{10 i}$ es beneficios para licitaciones y concursos; $X_{11 i}$ es Alivios fiscales; y $X_{12 i}$ es Que una parte del salario de los excombatientes lo pague un tercero. 
Para completar cada modelo logit multinomial se aplicaría la probabilidad de elección a las especificaciones anteriores:

$$
p_{i j}=\frac{e^{\beta_{j}^{\prime} X_{i}}}{\sum_{k=1}^{m} e^{\beta_{j}^{\prime} X_{i}}},
$$

donde $0 \leq p_{i j} \geq 1$ y $\sum_{k=1}^{m} P_{i j}=1$

\section{Resultados}

\subsection{Análisis descriptivo}

A continuación se realiza un análisis exploratorio de las principales variables de la encuesta de posacuerdo en Palmira, Candelaria, Florida y Pradera, a través de una segmentación de las preguntas en tres dimensiones: caracterización de los empresarios, caracterización de las empresas y decisión de contratar excombatientes. Esta segmentación se debe a la homogeneidad y características de las preguntas de la encuesta.

\subsubsection{Caracterización de los empresarios}

En esta sección analizamos las características de los empresarios encuestados. La Figura 1

muestra que la mayoría de los encuestados son hombres y tienen una participación significativa en cada categoría de decisión de contratación de excombatientes. Por otra parte, el nivel de estudios de los empresarios encuestados se exhibe en la Figura 2, la cual muestra que la mayoría de los empresarios indican tener estudios de educación superior, sugiriendo que un mayor nivel de estudio aumenta las posibilidades de contratación de los excombatientes. A su vez, la Figura 3 presenta la distribución de la edad de los empresarios encuestados: para las categorías Sí e Indecisos el rango de edad con mayor participación es de 30 a 45 años. En cambio, la categoría No tiene un rango de edad principal de 30 a 60 años, sugiriendo que los empresarios encuestados con menor edad están dispuestos a contratar a excombatientes, en una mayor proporción que los empresarios con mayor edad.

La distribución de la antigüedad del negocio o laboral se presenta en la Figura 4. Esta exhibe que la mayoría de las personas encargadas de tomar la decisión de contratar tiene un rango de antigüedad de 1 a 10 años para todas las categorías. Por su parte, la Figura 5 muestra las experiencias de los empresarios con quiebras de sus empresas, sugiriendo que ellos están dispuestos a contratar excombatientes en una mayor proporción que los empresarios sin estas experiencias.

\section{Figura 1. Género}

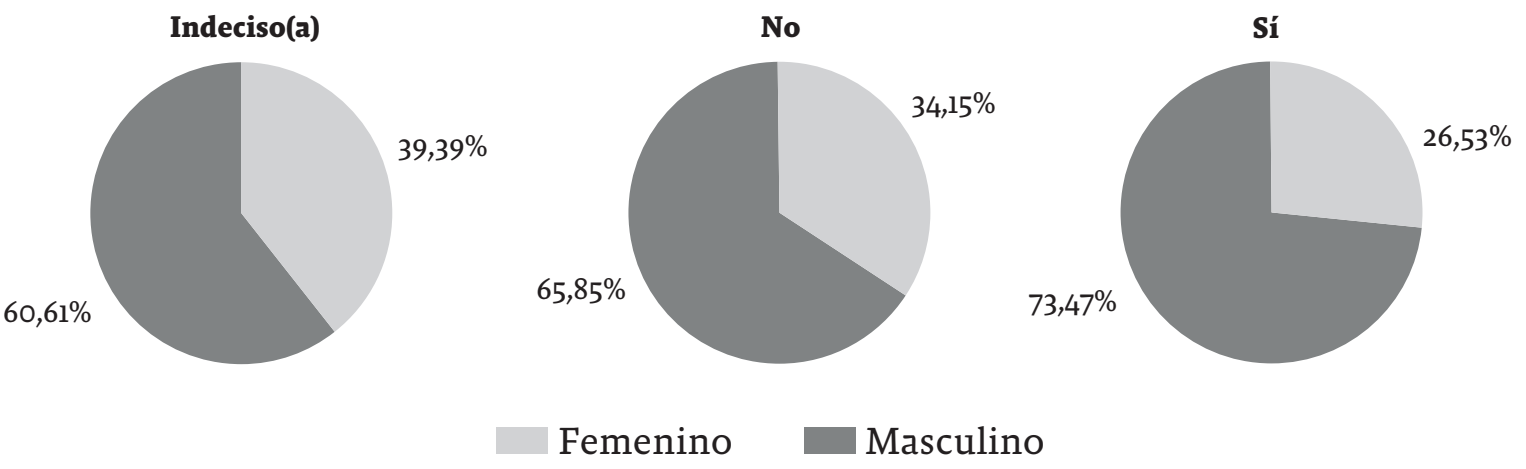

Fuente: elaboración propia. 
Figura 2. Nivel de Estudios

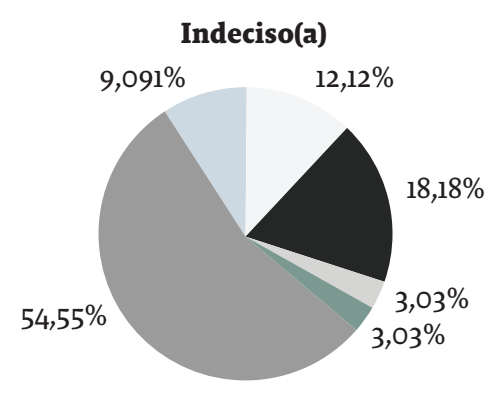

Otra / no responde

Posgrado sin terminar

Secundaria finalizada

Universidad pregrado finalizado
No

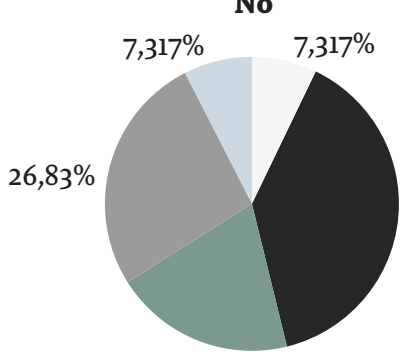

$19,51 \%$

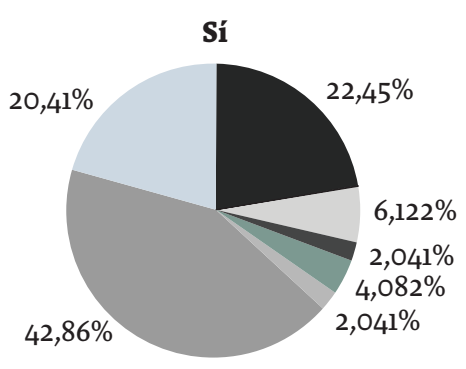

$39,02 \%$

Posgrado finalizado

Primaria

Secundaria sin terminar

Universidad pregrado sin terminar

Fuente: elaboración propia.

Figura 3. Edad

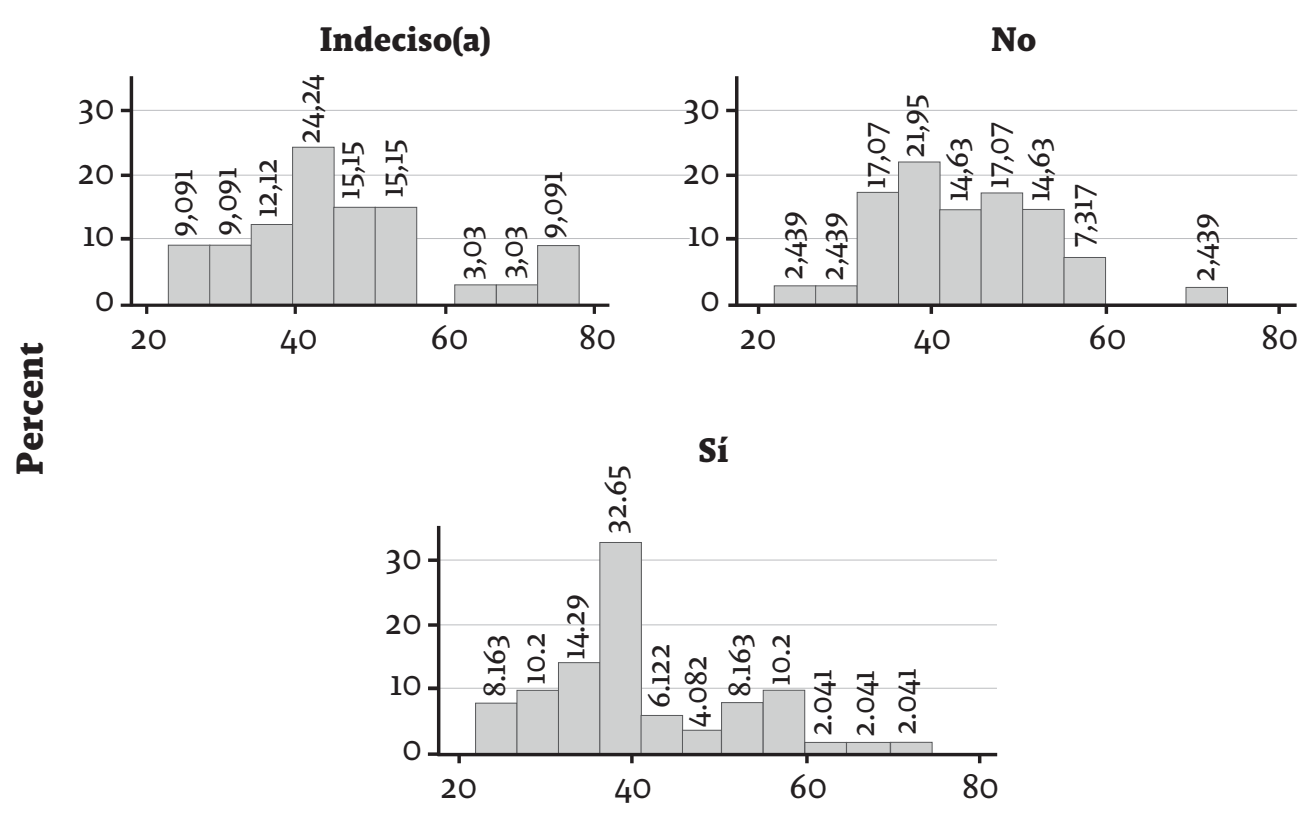

Fuente: elaboración propia. 
Figura 4. Antigüedad Laboral

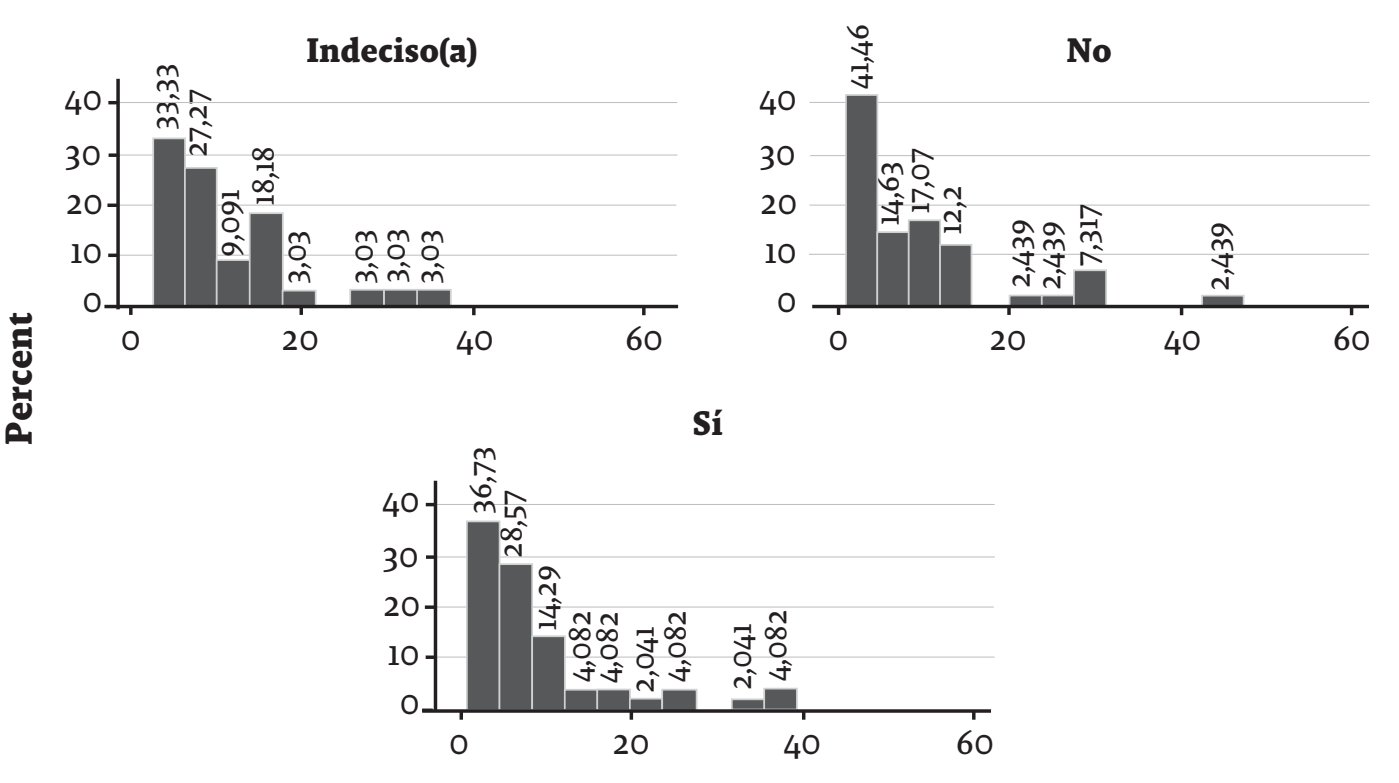

Fuente: elaboración propia.

Figura 5. Quiebras

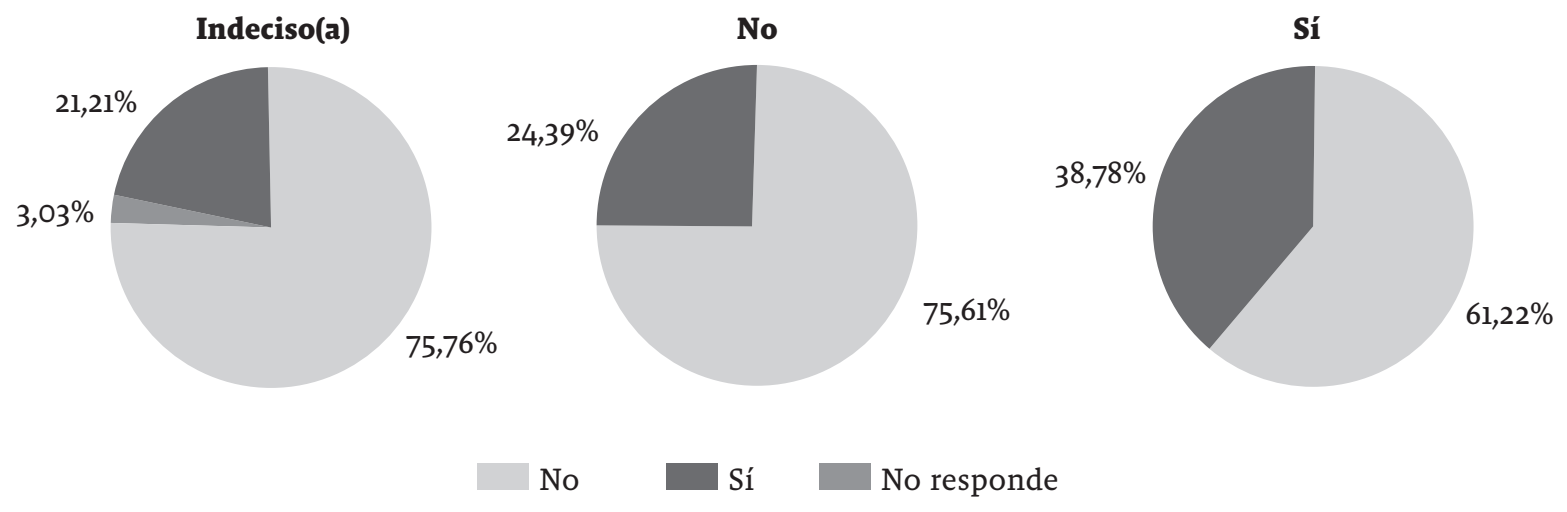

Fuente: elaboración propia. 
En términos generales, la mayoría de los encuestados son hombres con estudios de educación superior, en un rango de edad de 30 a 60 años, con una antigüedad en el cargo menor a 15 años, tienen algún tipo de participación en la empresa y estuvieron expuestos a fracasos o quiebras empresariales.

\subsubsection{Caracterización de las empresas}

En esta sección, analizamos las características de las empresas encuestadas. La Figura 6 muestra que la mayoría de las empresas encuestadas están compuestas por menos de 1000 empleados. A su vez, la distribución de los sectores económicos se presenta en la Figura 7: los sectores agropecuarios, comercio y servicios son más propensos a contratar excombatientes. Mientras, los sectores de construcción, financiero y solidario están más indecisos. En cambio, los sectores industriales, transporte u otro no tienen una categoría líder.
En resumen, las empresas encuestadas están compuestas por menos de 1000 empleados y, en mayor proporción, pertenecen a los sectores de servicios, comercio e industria.

\subsubsection{Vinculación laboral de excombatientes}

La investigación no se escapa de la polarización que está viviendo la sociedad colombiana respecto a este hecho histórico. Los empresarios encuestados están polarizados frente a la decisión de contratar a excombatientes en su planta de personal. Aproximadamente, el $40 \%$ de los empresarios contrataría a estos individuos. Sin embargo, aproximadamente el $33 \%$ no los vincularía. A su vez, $27 \%$ está indeciso(a) sobre esta cuestión tan importante para el futuro del país, como se muestra en la Tabla 1.

Figura 6. Número de Empleados
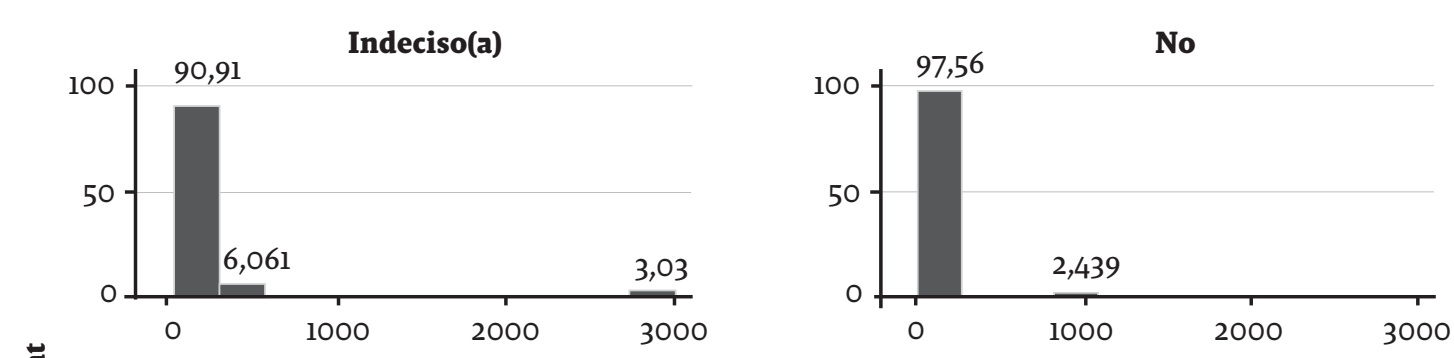

Sí

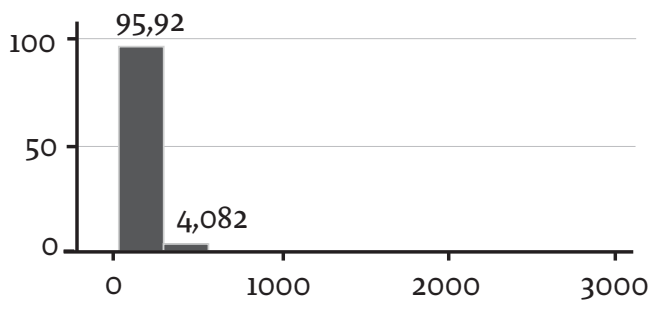

Fuente: elaboración propia. 
Figura 7. Sector Económico.

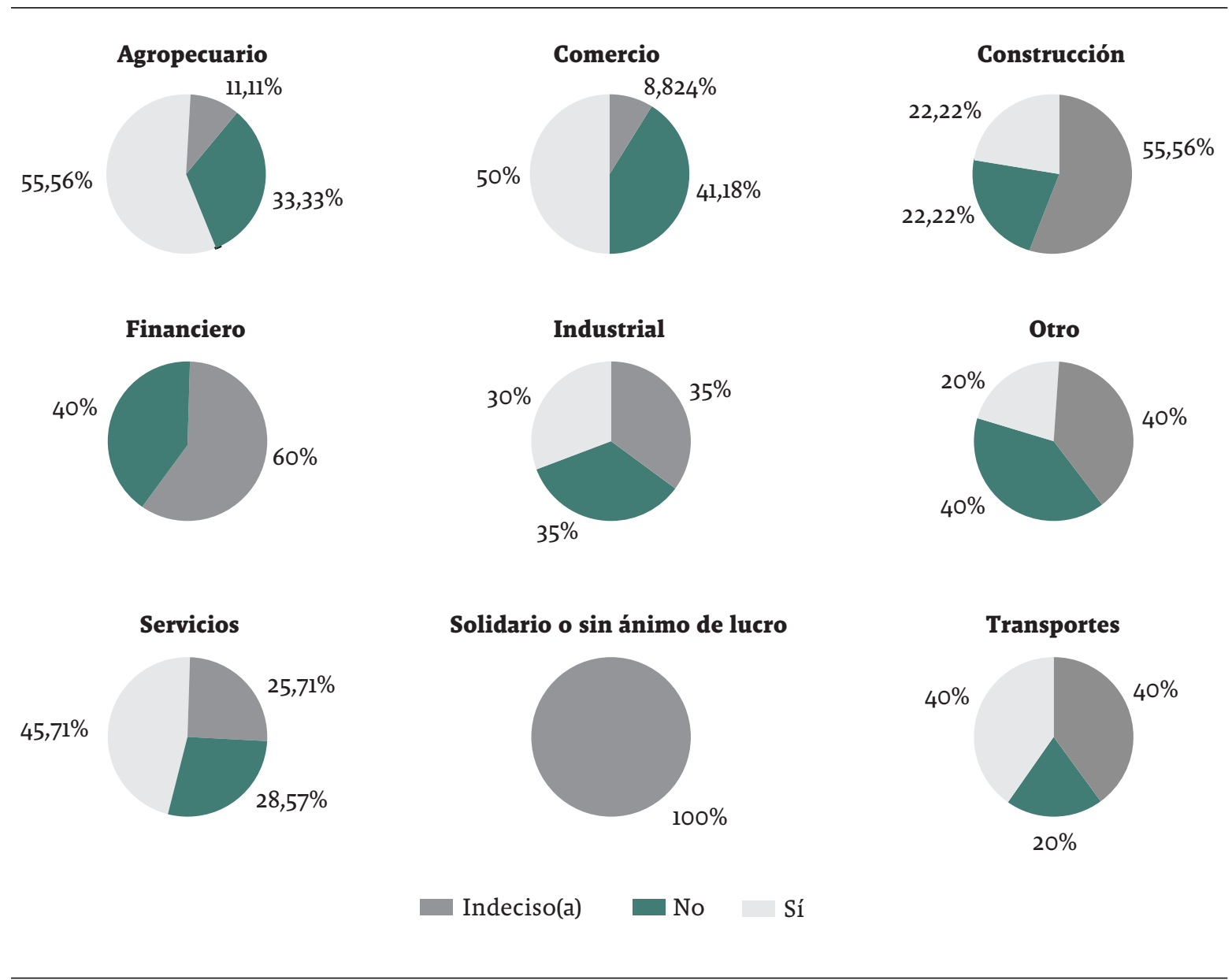

Fuente: elaboración propia.

Tabla 1. ¿Su empresa emplearía excombatientes?

\begin{tabular}{cccc}
\hline $\begin{array}{c}\text { Su empresa emplearía } \\
\text { excombatientes }\end{array}$ & $\begin{array}{c}\text { Frecuencia } \\
\text { Absoluta }\end{array}$ & $\begin{array}{c}\text { Frecuencia } \\
\text { Relativa }\end{array}$ & $\begin{array}{c}\text { Frecuencia Relativa } \\
\text { Acumulada }\end{array}$ \\
\hline Indeciso (a) & 33 & 26,83 & 26,83 \\
\hline No & 41 & 33,33 & 60,16 \\
\hline Sí & 49 & 39,84 & 100 \\
\hline Total & 123 & 100 & - \\
\hline
\end{tabular}

Nota: la tabla informa la decisión de los empleadores sobre la contratación de excombatientes.

Fuente: elaboración propia. 


\subsection{Modelo Base}

A continuación, se presentan las probabilidades de cada categoría de decisión de los empleadores con respecto a la contratación de excombatientes, que se derivan de la estimación del modelo base.

La Tabla 2 muestra la probabilidad de cada una de las categorías de la variable dependiente "¿Su empresa emplearía excombatientes?", después de estimar los efectos marginales de las variables independientes. Estos resultados confirman los hallazgos del análisis descriptivo: los empresarios encuestados están polarizados sobre esta decisión tan importante para el futuro del país. Además, la categoría de "no contratar" logra mayor probabilidad que la categoría de "indecisos".

McMullin (2013) encuentra que los programas de reintegración que establecen una ayuda a largo plazo a los excombatientes, exacerban el resentimiento de la población y la estigmatización hacia ellos, atentando contra el objetivo del programa. Igualmente, el Consejo Nacional de Política Económica y Social (Conpes, 2008) informa que esta situación se presenta por factores comunitarios e institucionales. Los primeros tienen relación con la estigmatización y el poco apoyo por parte de las comunidades receptoras o el miedo a represarías de GAI activos por acogerlos. Adicionalmente, la desconfianza y resentimiento en la sociedad en general, dado que se puede percibir a los DDR como programas exclusivos y poco equitativos frente a las víctimas del conflicto armado o población vulnerable.

\subsubsection{Efectos Marginales}

A continuación, se presentan los efectos marginales del modelo logit multinomial estimado.
Como se observa en los efectos marginales de la Tabla 3, las variables de edad, antigüedad laboral y número de empleados presentan efectos marginales de magnitudes muy pequeñas. En términos generales, a medida que aumenta el nivel educativo de los encuestados, disminuye la probabilidad de las categorías de Indecisión y No; en cambio, en la categoría de Sí, aumenta su probabilidad. Lo cual sugiere que la educación elimina las ideas preconcebidas y estigmatizadoras de los empresarios al momento de contratar a un excombatiente.

Por otra parte, respecto al cargo del encuestado, a medida que aumenta la posición jerárquica disminuye la probabilidad de Indecisión. En cuanto a la categoría del No, en los cargos de jerarquía baja, la probabilidad disminuye. En cambio, a medida que aumenta la posición de poder del encuestado, aumenta la probabilidad de esta categoría. Por último, los cargos relacionados con la gestión humana de las empresas encuestadas, disminuyen la probabilidad de la categoría del Sí. Sin embargo, los demás cargos favorecen el aumento en la probabilidad de esta categoría.

A su vez, los encuestados expuestos a quiebras o fracasos disminuyen la probabilidad de las categorías del No e Indeciso(a). En contraste, aumentan en un $32 \%$ la probabilidad de la categoría del Sí. Los empresarios con experiencias de quiebras empresariales tienden a comprender con mayor facilidad la posibilidad de segundas oportunidades en la vida, la cual podría ser la razón de que acepten con menores prejuicios a los excombatientes.

En cuanto al género, los hombres disminuyen la probabilidad de las categorías de Indeciso(a) y No, en comparación con las mujeres encuestadas. Caso contrario se presenta en la

Tabla 2. Probabilidades de los efectos marginales

\begin{tabular}{lccc}
\hline Variable Dependiente & Indeciso(a) & No & Sí \\
\hline Probabilidad & 0,10000422 & 0,532958 & 0,3670379 \\
\hline Fuente: elaboración propia. & & & \\
\hline
\end{tabular}


categoría del Sí: los hombres aumentan un 24\% la probabilidad de esta categoría en relación a las mujeres. Este hallazgo sugiere que se debe investigar la injerencia del enfoque de género en la decisión de contratar excombatientes.
Por último, la variable de sector económico y la categoría de Indeciso(a) muestran el siguiente comportamiento: la mayoría de las categorías aumentan la probabilidad de Indecisión, solo el sector de transporte disminuye la probabilidad,

Tabla 3. Efectos marginales

\begin{tabular}{|c|c|c|c|c|c|c|c|}
\hline Categoría & Indeciso(a) & No & Sí & Categoría & Indeciso(a) & No & Sí \\
\hline Variables & $\mathrm{dy} / \mathrm{dx}$ & $\mathrm{dy} / \mathrm{dx}$ & $\mathrm{dy} / \mathrm{dx}$ & Variables & $\mathrm{dy} / \mathrm{dx}$ & $d y / d x$ & $d y / d x$ \\
\hline Edad & 0,0049385 & $-0,00062$ & $-0,004317$ & _ICar 16*| & $-0,1464722$ & 0,203334 & 0,2202742 \\
\hline Sexo_Mas & $-0,1572989$ & $-0,08694$ & 0,2442371 & _ICar $\sim 17^{*} \mid$ & $-0,1526132$ & 0,30476 & $-0,38632$ \\
\hline _IEduc 2*| & $-0,1114783$ & $-0,58931$ & 0,7007928 & _ICar $\sim 18^{\star} \mid$ & $-0,1546361$ & 0,477877 & 0,4472056 \\
\hline _IEduc $3^{*} \mid$ & $-0,1114709$ & $-0,58683$ & 0,6983007 & _ICar 19*| & $-0,159125$ & 0,521315 & 0,0961874 \\
\hline _IEduc $\sim 4^{*} \mid$ & $-0,2049235$ & $-0,68708$ & 0,8920006 & _ICar 20*| & $-0,1763671$ & 0,523234 & 0,6799915 \\
\hline _IEduc $5^{*}$ & $-0,7114727$ & $-0,27243$ & 0,9839024 & _ICar $\sim 21^{*} \mid$ & $-0,1916048$ & 0,530693 & $-0,406481$ \\
\hline _IEduc $6^{*} \mid$ & $-0,4177801$ & $-0,58195$ & 0,9997267 & _ICar 22*| & $-0,1948513$ & 0,535208 & $-0,392166$ \\
\hline _IEduc $\sim 7^{\star} \mid$ & $-0,0904479$ & $-0,74746$ & 0,8379093 & _ICar 23*| & $-0,3748701$ & 0,552784 & 0,2001697 \\
\hline _IEduc $8^{\star} \mid$ & $-0,5450456$ & $-0,45186$ & 0,996903 & _ICar $24^{*} \mid$ & $-0,9912468$ & 0,575463 & 0,676929 \\
\hline _ICar _2*| & $-0,0220603$ & $-0,56213$ & 0,5187853 & _ICar $25^{*} \mid$ & $-0,996662$ & 0,583771 & 0,676496 \\
\hline _ICar _3*I & $-0,0955589$ & $-0,54236$ & 0,5089687 & _ICar $26^{*} \mid$ & $-0,99999$ & 0,601332 & $-0,08555$ \\
\hline _ICar _4*I & $-0,1118259$ & $-0,53661$ & $-0,385506$ & Antigüedad & $-0,0045143$ & 0,00459 & $-0,000075$ \\
\hline _ICar _5*| & $-0,1123296$ & $-0,53173$ & 0,403963 & Ex. Quiebras 3 & $-0,0191096$ & $-0,29945$ & 0,3185622 \\
\hline _ICar _6* & $-0,1125927$ & $-0,52602$ & 0,6788955 & N. Empleados & 0,0029089 & $-0,00638$ & 0,003467 \\
\hline _ICar _7*I & $-0,113672$ & $-0,51737$ & $-0,381129$ & _ISect $2 * \mid$ & 0,0996791 & 0,15801 & $-0,257689$ \\
\hline _ICar _8*| & $-0,1358095$ & $-0,45302$ & 0,6637077 & _ISect $3^{*} \mid$ & 0,8847779 & $-0,44606$ & $-0,438723$ \\
\hline _ICar _9*| & $-0,1376309$ & $-0,36384$ & $-0,388736$ & _ISect $\sim 4^{*} \mid$ & 0,9285783 & $-0,35784$ & $-0,570739$ \\
\hline _ICar 10*| & $-0,1376845$ & $-0,29163$ & $-0,399096$ & _ISect $\sim 5^{*}$ & 0,5578466 & $-0,17994$ & $-0,377911$ \\
\hline _ICar $\sim 11^{*}$ & $-0,1421051$ & $-0,04553$ & 0,7147437 & _ISect $\sim 6^{*} \mid$ & 0,8510024 & $-0,49016$ & $-0,360841$ \\
\hline _ICar 12*| & $-0,1422856$ & 0,016405 & $-0,191088$ & _ISect $\sim 7^{*} \mid$ & 0,4194181 & $-0,17627$ & $-0,243146$ \\
\hline _ICar 13*| & $-0,1443732$ & 0,10761 & 0,7879126 & _ISect $\sim 8^{*}$ & 0,9274877 & $-0,54351$ & $-0,38398$ \\
\hline _ICar 14*| & $-0,1451296$ & 0,154596 & 0,5648501 & _ISect $\sim 9^{*} \mid$ & $-0,1657751$ & 0,288724 & $-0,122949$ \\
\hline _ICar 15*| & $-0,1451999$ & 0,155356 & $-0,059797$ & & & & \\
\hline
\end{tabular}

Nota: la tabla muestra los efectos marginales del modelo con las características de los empleadores y las MIPYME.

Fuente: elaboración propia. 
en comparación con el sector agropecuario. En cambio, en las categorías del Sí y No, la mayoría de los sectores económicos disminuyen la probabilidad de ambas categorías en relación al sector agropecuario.

\subsection{Ampliación del Modelo Base}

En esta sección se realiza la ampliación del modelo base en dos segmentos de las variables: procesos de paz y políticas de incentivos a la demanda laboral.

Como se hace imposible una descripción exhaustiva de todos los resultados por cuestiones de espacio, se presentan los resultados más importantes y, en particular, se realiza una descripción de las probabilidades relativas (Odds Ratios) y la probabilidad de los efectos marginales.

\subsubsection{Proceso de Paz}

En esta sección se presentan las probabilidades de cada categoría de decisión de los empleadores con respecto a la contratación de excombatientes, que se derivan de la estimación de cuatro modelos. Como se observa en la Tabla 4, Tabla 5 y Tabla 6, en términos generales, la inclusión de las percepciones de los empresarios sobre el proceso de paz, tiende a disminuir la probabilidad de la categoría Sí, en favor de las categorías del No e Indeciso(a). Esto puede indicar que las valoraciones de los empresarios sobre el proceso de paz afectarían la posibilidad de vinculación laboral de los excombatientes. Este resultado concuerda con Hinestroza, Santamaría y Rubio (2016): las percepciones de los empresarios en relación a la vinculación laboral de los excombatientes no son del todo positivas.

Dicha percepción puede estar relacionada con que las características psicológicas de las personas en proceso de reintegración son resultado de la interacción en contextos familiares, sociales, culturales, económicos y políticos, caracterizados por la violencia, injusticia e inequidad, que dificultan la posibilidad de generar alternativas para la satisfacción de sus necesidades básicas. Estas personas enfrentan los temores propios de un cambio de vida radical, que exige acoplarse a un medio "civil", donde los códigos y privilegios a los que estaban acostumbrados ya no son válidos (Conpes, 2008).

Teniendo en cuenta este resultado, el proceso de Desarme, Desmovilización y Reintegración (DDR) y La Agencia para la Reincorporación y la Normalización (ARN), buscarían focalizar sus estrategias en la sensibilización y acompañamiento al sector empresarial, para la vinculación laboral de los excombatientes. Además, la articulación de los DDR y ARN con las iniciativas de las agremiaciones empresariales -como las Cámaras de Comercio de las ciudades del paísque generen espacios de convivencia y cooperación en el sector empresarial, estimulando la creación de esferas de reconciliación.

\subsubsection{Políticas de incentivos a la vinculación de excombatientes}

A continuación, se presentan las probabilidades de cada categoría de decisión de los empleadores con respecto a la contratación de

\begin{tabular}{lccc}
\hline \multicolumn{4}{c}{ Tabla 4. Probabilidades de los efectos marginales } \\
\hline Modelo & Indeciso(a) & No & Sí \\
\hline Base & 0,1 & 0,533 & 0,367 \\
\hline Base Reducido & 0,410 & 0,365 & 0,225 \\
\hline Percepciones del Proceso de Paz & 0,316 & 0,583 & 0,101 \\
\hline Base Reducido y Percepciones del Proceso de Paz & 0,366 & 0,616 & 0,018 \\
\hline Fuente: elaboración propia. & & & \\
\hline
\end{tabular}


Tabla 5. Probabilidades Relativas (Odds Ratios). Modelo de Percepciones del Proceso de Paz

\begin{tabular}{|c|c|c|c|c|c|}
\hline $\begin{array}{c}\text { Odds } \\
\text { comparing: } \\
\text { Alternative } 1 \text { to } \\
\text { Alternative } 2\end{array}$ & $\begin{array}{c}\text { ¿Está usted de } \\
\text { acuerdo con lo } \\
\text { firmado entre } \\
\text { el gobierno } \\
\text { nacional y las } \\
\text { FARC EP? }\end{array}$ & $\begin{array}{l}\text { ¿Por qué está } \\
\text { de acuerdo } \\
\text { con lo firmado } \\
\text { entre el } \\
\text { gobierno } \\
\text { nacional y las } \\
\text { FARC EP? }\end{array}$ & $\begin{array}{c}\text { ¿Por qué } \\
\text { está en } \\
\text { desacuerdo } \\
\text { con el } \\
\text { proceso con } \\
\text { las FARC? }\end{array}$ & $\begin{array}{l}\text { ¿Usted conoce } \\
\text { algún programa } \\
\text { de reintegración } \\
\text { del Gobierno } \\
\text { Nacional para } \\
\text { excombatientes? }\end{array}$ & $\begin{array}{l}\text { ¿Cuál es el } \\
\text { principal desafío } \\
\text { del posconflicto? }\end{array}$ \\
\hline No - Sí & 0,6451 & 0,7648 & 0,8767 & 1,1815 & 0,9808 \\
\hline No - Indeciso(a) & 0,9408 & 0,9724 & 0,9993 & 2,3685 & 1,0010 \\
\hline Sí - No & 1,5502 & 1,3075 & 1,1406 & 0,8464 & 1,0196 \\
\hline Sí - Indeciso(a) & 1,4585 & 1,2714 & 1,1398 & 2,0047 & 1,0206 \\
\hline Indeciso(a) - No & 1,06290 & 1,0284 & 1,0007 & 0,4222 & 0,9990 \\
\hline Indeciso(a) - Sí & 0,6856 & 0,7865 & 0,8773 & 0,4988 & 0,9798 \\
\hline
\end{tabular}

Nota: la tabla informa los odds ratios de cada categoría de decisión de los empleadores con respecto a la contratación de excombatientes para las preguntas del modelo "percepciones del proceso de paz."

Fuente: elaboración propia.

Tabla 6. Probabilidades Relativas (Odds Ratios). Modelo Base Reducido y Percepciones del Proceso de Paz

\begin{tabular}{lccccc}
\hline $\begin{array}{c}\text { Odds comparing: } \\
\text { Alternative 1 to } \\
\text { Alternative 2 }\end{array}$ & $\begin{array}{c}\text { ¿Está usted de } \\
\text { acuerdo con lo } \\
\text { firmado entre } \\
\text { el gobierno } \\
\text { nacional y las } \\
\text { FARC EP? }\end{array}$ & $\begin{array}{c}\text { acuerdo con lo } \\
\text { firmado entre } \\
\text { el gobierno } \\
\text { nacional y las } \\
\text { FARC EP? }\end{array}$ & $\begin{array}{c}\text { ¿Por qué } \\
\text { está en } \\
\text { desacuerdo } \\
\text { con el } \\
\text { proceso con } \\
\text { las FARC? }\end{array}$ & $\begin{array}{c}\text { ¿Usted conoce } \\
\text { algún programa } \\
\text { de reintegración } \\
\text { del Gobierno } \\
\text { Nacional para } \\
\text { excombatientes? }\end{array}$ & $\begin{array}{c}\text { iCuál es el } \\
\text { principal desafío } \\
\text { del posconflicto? }\end{array}$ \\
\hline No - Sí & 0,7388 & 0,6581 & 0,8618 & 1,1003 & 0,9777 \\
\hline No - Indeciso(a) & 1,1632 & 0,8753 & 0,9847 & 2,3397 & 0,9697 \\
\hline Sí - No & 1,3536 & 1,5194 & 1,1603 & 0,9088 & 1,0228 \\
\hline Sí - Indeciso(a) & 1,5745 & 1,3299 & 1,1426 & 2,1264 & 0,9918 \\
\hline Indeciso(a) - No & 0,8597 & 1,1425 & 1,0155 & 0,4274 & 1,0313 \\
\hline Indeciso(a) - Sí & 0,6351 & 0,7519 & 0,8752 & 0,4703 & 1,0083 \\
\hline
\end{tabular}

Nota: la tabla informa los odds ratios de cada categoría de decisión de los empleadores con respecto a la contratación de excombatientes para las preguntas del modelo "Bases reducidas y percepciones del proceso de paz".

Fuente: elaboración propia. 
excombatientes, que se derivan de la estimación de los modelos relacionados con las percepciones de las políticas de incentivos. La Tabla 7 muestra que la inclusión de las actitudes de los empresarios, en relación a las políticas de incentivos por parte del gobierno para vincular excombatientes, tiende a disminuir en términos generales la probabilidad de la categoría Sí en relación a las demás variables. Esto coincide con los hallazgos de CCB (2015), teniendo en cuenta que el gobierno no es muy claro en las propuestas y manejó una baja socialización de las políticas de incentivos al sector empresarial. También coincide con Velasco (2006), quien sostiene que se han presentado problemas institucionales que no permiten concretar una participación mucho más significativa del sector empresarial.

No obstante, cuando se analizan los odds ratios de la Tabla 8 y la Tabla 9 se evidencia que existen oportunidades para políticas de incentivos del gobierno, lo cual podría cambiar la decisión de los empresarios a favor de una vinculación laboral de los excombatientes. Los incentivos que generarían el mayor impacto positivo serían los alivios fiscales y el mayor reconocimiento para su empresa; en una menor medida, el Apoyo para la comercialización de sus productos. En cuanto a los otros incentivos, el proceso de Desarme, Desmovilización y Reintegración (DDR) y La Agencia para la Reincorporación y la Normalización (ARN) buscarían una mayor divulgación, socialización y claridad de las políticas de incentivos del gobierno.

Estas oportunidades concuerdan con Rettberg (2013): si el sector empresarial percibe que los beneficios esperados de la paz (alivios fiscales y el mayor reconocimiento para su empresa) son mayores a los costos esperados del conflicto, entonces participaría activamente.

\section{Conclusiones}

Este artículo estima un modelo empírico, útil para la cuantificación y el análisis de las percepciones de los empresarios sobre la vinculación laboral de excombatientes en sus empresas. La metodología modela las características de los empresarios y sus empresas con las percepciones de estos sobre el proceso de paz y las políticas de incentivos del gobierno. A su vez, la literatura académica que aborda las percepciones de los empresarios sobre las condiciones de la demanda laboral, desde el punto de vista económico, plantea la influencia de las actitudes de ellos sobre sus decisiones de contratación. En este trabajo se demuestra que, efectivamente, las percepciones de los empresarios sobre el proceso de paz y las políticas de incentivos del gobierno influyen en las decisiones de los empresarios sobre la contratación de excombatientes en sus empresas. Por lo tanto, estos hallazgos son muy importantes en términos de políticas públicas, proceso de paz y el futuro del país.

Los resultados evidencian la polarización que está viviendo la sociedad colombiana respecto a este hecho histórico. Los empresarios están polarizados frente a la decisión de contratar a excombatientes en su planta de personal. Aproximadamente, el $40 \%$ de los empresarios

Tabla 7. Probabilidades de los efectos marginales

\begin{tabular}{lccc}
\hline Modelo & Indeciso(a) & No & Sí \\
\hline Base & 0,1 & 0,533 & 0,367 \\
\hline Base Reducido & 0,410 & 0,365 & 0,225 \\
\hline Percepciones de las Políticas de incentivos & 0,435 & 0,548 & 0,016 \\
\hline Base Reducido y Percepciones de las Políticas de incentivos & 0,492 & 0,474 & 0,033 \\
\hline
\end{tabular}

Fuente: elaboración propia. 
Tabla 8. Probabilidades Relativas (Odds Ratios). Modelo de Percepciones del Proceso de Paz

\begin{tabular}{|c|c|c|c|c|c|c|}
\hline $\begin{array}{c}\text { Odds } \\
\text { comparing: } \\
\text { Alternative } 1 \text { to } \\
\text { Alternative } 2\end{array}$ & $\begin{array}{c}\text { ¿Cambiaría de } \\
\text { opinión ante } \\
\text { los siguientes } \\
\text { beneficios? } \\
\text { [Apoyo para la } \\
\text { comercialización } \\
\text { de sus } \\
\text { productos] }\end{array}$ & $\begin{array}{l}\text { ¿Cambiaría } \\
\text { de opinión } \\
\text { ante los } \\
\text { siguientes } \\
\text { beneficios? } \\
\text { [Acceso a } \\
\text { tecnología } \\
\text { a menor } \\
\text { costo] }\end{array}$ & $\begin{array}{c}\text { ¿Cambiaría de } \\
\text { opinión ante } \\
\text { los siguientes } \\
\text { beneficios? } \\
\text { [Mayor } \\
\text { reconocimiento } \\
\text { para su empresa] }\end{array}$ & $\begin{array}{c}\text { ¿Cambiaría } \\
\text { de opinión } \\
\text { ante los } \\
\text { siguientes } \\
\text { beneficios? } \\
\text { [Beneficios } \\
\text { para } \\
\text { licitaciones y } \\
\text { concursos] }\end{array}$ & $\begin{array}{l}\text { ¿Cambiaría } \\
\text { de opinión } \\
\text { ante los } \\
\text { siguientes } \\
\text { beneficios? } \\
\text { [Alivios } \\
\text { fiscales] }\end{array}$ & $\begin{array}{c}\text { ¿Cambiaría de } \\
\text { opinión ante } \\
\text { los siguientes } \\
\text { beneficios? } \\
\text { [Que una parte } \\
\text { del salario de los } \\
\text { excombatientes } \\
\text { lo pague un } \\
\text { tercero] }\end{array}$ \\
\hline No - Sí & 0,6755 & 0,3648 & 1,1096 & 0,7365 & 1,5329 & 0,7044 \\
\hline No-Indeciso(a) & 0,3066 & 1,2460 & 0,7376 & 0,8317 & 0,9255 & 0,6986 \\
\hline Sí - No & 1,4803 & 2,7415 & 0,9013 & 1,3578 & 0,6524 & 1,4197 \\
\hline Sí- Indeciso(a) & 0,4538 & 3,4160 & 0,6648 & 1,1293 & 0,6038 & 0,9918 \\
\hline Indeciso(a)-No & 3,2618 & 0,8025 & 1,3557 & 1,2023 & 1,0805 & 1,4314 \\
\hline Indeciso(a) - Sí & 2,2034 & 0,2927 & 1,5042 & 0,8855 & 1,6562 & 1,0082 \\
\hline
\end{tabular}

Nota: la tabla informa los odds ratios de cada categoría de decisión de los empleadores con respecto a la contratación de excombatientes para las preguntas del modelo "Percepciones de las políticas de incentivos".

Fuente: elaboración propia.

Tabla 9. Probabilidades Relativas (Odds Ratios). Modelo Base Reducido y Percepciones del Proceso de Paz

\begin{tabular}{|c|c|c|c|c|c|c|}
\hline $\begin{array}{c}\text { Odds } \\
\text { comparing: } \\
\text { Alternative } 1 \text { to } \\
\text { Alternative } 2\end{array}$ & $\begin{array}{l}\text { ¿Cambiaría de } \\
\text { opinión ante } \\
\text { los siguientes } \\
\text { beneficios? } \\
\text { [Apoyo para la } \\
\text { comercialización } \\
\text { de sus productos] }\end{array}$ & $\begin{array}{c}\text { ¿Cambiaría } \\
\text { de opinión } \\
\text { ante los } \\
\text { siguientes } \\
\text { beneficios? } \\
\text { [Acceso a } \\
\text { tecnología a } \\
\text { menor costo] }\end{array}$ & $\begin{array}{c}\text { ¿Cambiaría de } \\
\text { opinión ante } \\
\text { los siguientes } \\
\text { beneficios? } \\
\text { [Mayor } \\
\text { reconocimiento } \\
\text { para su } \\
\text { empresa] }\end{array}$ & $\begin{array}{c}\text { ¿Cambiaría } \\
\text { de opinión } \\
\text { ante los } \\
\text { siguientes } \\
\text { beneficios? } \\
\text { [Beneficios } \\
\text { para } \\
\text { licitaciones y } \\
\text { concursos] }\end{array}$ & $\begin{array}{c}\text { ¿Cambiaría } \\
\text { de opinión } \\
\text { ante los } \\
\text { siguientes } \\
\text { beneficios? } \\
\text { [Alivios } \\
\text { fiscales] }\end{array}$ & $\begin{array}{c}\text { ¿Cambiaría de } \\
\text { opinión ante } \\
\text { los siguientes } \\
\text { beneficios? } \\
\text { [Que una parte } \\
\text { del salario de los } \\
\text { excombatientes } \\
\text { lo pague un } \\
\text { tercero] }\end{array}$ \\
\hline No - Sí & 0,7732 & 0,3844 & 1,0698 & 0,6547 & 1,7019 & 0,6538 \\
\hline No- Indeciso(a) & 0,2552 & 1,6155 & 0,7638 & 0,6888 & 0,8706 & 0,7463 \\
\hline Sí - No & 1,2933 & 2,6013 & 0,9347 & 1,5274 & 0,5876 & 1,5295 \\
\hline Sí- Indeciso(a) & 0,3300 & 4,2023 & 0,7139 & 1,0520 & 0,5116 & 1,1414 \\
\hline Indeciso(a) - No & 3,9186 & 0,6190 & 1,3093 & 1,4519 & 1,1486 & 1,3400 \\
\hline Indeciso(a) - Sí & 3,0299 & 0,2380 & 1,4007 & 0,9506 & 1,9548 & 0,8761 \\
\hline
\end{tabular}

Nota: la tabla informa los odds ratios probabilidad de cada categoría de decisión de los empleadores con respecto a la contratación de excombatientes para las preguntas del modelo "Bases reducidas y percepciones de las políticas de incentivos".

Fuente: elaboración propia. 
contrataría a estos individuos. Sin embargo, aproximadamente el $33 \%$ no los vincularía. A su vez, el $27 \%$ está indeciso(a) sobre esta cuestión tan importante para el futuro del país. Encontramos que las percepciones de los empresarios respecto al proceso de paz afectan de forma negativa la vinculación laboral de los excombatientes. En parte, debido a que este proceso se relaciona con un gobierno en específico y no como una política de estado que busque el máximo bienestar social del país. No obstante, los resultados reflejan que las políticas de incentivos del gobierno pueden generar un efecto positivo sobre las decisiones de contratación de los empresarios, especialmente, los alivios fiscales y el mayor reconocimiento empresarial. Por último, se debe estimar la articulación entre ARN y las agremiaciones empresariales para generar espacios de convivencia, cooperación y reconciliación.

\section{Referencias bibliográficas}

Berdal, M. y Zaum, D. (2013). Political Economy of Statebuilding: Power after Peace. Nueva York, Estados Unidos: Routledge.

Bowd, R. y Özerdem, A. (2013). How to Assess Social Reintegration of Ex-Combatants. Journal of Intervention and Statebuilding, 7(4), 1-23. https://doi.org/10.1080/17502977.2012.727537

CCB -Cámara de Comercio de Bogotá-. (2015). Perspectivas y aportes empresariales para la construcción de paz. Recuperado de https://www.ccb.org.co/content/download/7210/97986/version/1/file/ Perspectivas+y+aportes+empresariales+para+la+construccion+de+paz+final.pdf

CCB -Cámara de Comercio de Bogotá- y FiP -Fundación Ideas para la Paz-. (2015). Guía "Cómo apoyar iniciativas de empleabilidad de personas en proceso de reintegración (PPR) desde el sector empresarial". Recuperado de http://bibliotecadigital.ccb.org.co/bitstream/handle/11520/14038/13\%20 reintegracion\%20economica\%20y\%20empresas.pdf? sequence=lyisAllowed=y

Conpes -Consejo Nacional de Política Económica y Social-. (2008). Política nacional de reintegración social y económica para personas y grupos armados ilegales. Recuperado de https://www. reintegracion.gov.co/es/la-reintegracion/centro-de-documentacion/Documentos/Documento\%20 Conpes\%203554\%201\%20Pol\%C3\%ADtica\%20nacional\%20de\%20reintegraci\%C3\%B3n\%20 social\%20y\%20econ\%C3\%B3mica\%20para\%20personas\%20y\%20grupos\%20armados\%20ilegales. pdf

Denissen, M. (2010). Reintegrating Ex-Combatants into Civilian Life: The Case of the Paramilitaries in Colombia. Peace \& Change, 35(2), 328-352. https://doi.org/10.1111/j.1468-0130.2009.00630.x

De Vries, H. y Wiegink, N. (2011). Breaking up and going home? Contesting two assumptions in the demobilization and reintegration of former combatants. International Peacekeeping, 18(1), 38-51. https://doi.org/10.1080/13533312.2011.527506

Ehrenberg, R. y Smith, R. (2012). Modern Labor Economics Theory and Public Policy. Boston, Estados Unidos: Prentice Hall.

Guáqueta, A. (2006). Operando en medio del conflicto: construcción de paz y algunas mejores prácticas de empresas colombianas. Bogotá, Colombia: International Alert - Fundación Ideas para la Paz. Recuperado de https://www.files.ethz.ch/isn/151592/working_papers_fip2.pdf 
Guáqueta, A. y Orsini, Y. (2007). Empresarios y reintegración: casos, experiencias y lecciones. Recuperado de https://www.files.ethz.ch/isn/151588/empresarios_web.pdf

Hinestroza, M. P. G., Santamaría, M. L., y Rubio, M. C. A. (2016). Retos Para La Reintegración Efectiva de Excombatientes Irregulares en Colombia: Perspectiva de Empleabilidad. En J. R. Herrera e I. D. Jaramillo (Eds.), El trabajo como elemento de construcción de paz y democracia en el marco del posconflicto colombiano: Enseñanzas de un caso colombiano (pp. 163-192). Bogotá, Colombia: Universidad Del Rosario.

Iglesias, M. (2017). Aliados de la reintegración: una mirada estratégica de sus aportes. En, Agencia para la Reincorporación y la Normalización (ARN) (Ed.), Anuario de Reintegración 2017, (pp. 210-227). Bogotá, Colombia: ARN. Recuperado de http://www.reincorporacion.gov.co/es/la-reintegracion/ centro-de-documentacion/Documentos/Anuario\%20ARN\%202017.pdf

International Crisis Group. (2003). Disarmament and Reintegration in Afghanistan, Asia Report No 65. Recuperado de https://www.crisisgroup.org/asia/south-asia/afghanistan/ disarmament-and-reintegration-afghanistan

Kaplan, O.yNussio,E.(2015).Communitycounts:The social reintegration of ex-combatants in Colombia. Conflict Management and Peace Science, 35(2), 132-153. https://doi.org/10.1177/0738894215614506

Katchova,A.(2013).EconometricsAcademyin EconometricsAcademy. Recuperado de https://sites.google. com/site/econometricsacademy/econometrics-models/multinomial-probit-and-logit-models

Lopez, M. R. Andreouli, E. y Howarth, C. (2015). From ex-combatants to citizens: Connecting everyday citizenship and social reintegration in Colombia. Journal of Social and Political Psychology, 3(2), 171-191. https://doi.org/10.5964/jspp.v3i2.388

McMullin, J. R. (2013). Integration or separation? The stigmatisation of ex-combatants after war. Review of international studies, 39(2), 385-414. https://doi.org/10.1017/S0260210512000228

Munive, J. y Jakobsen, S. F. (2012). Revisiting DDR in Liberia: exploring the power, agency and interests of local and international actors in the 'making' and 'unmaking'of combatants. Conflict, Security y Development, 12(4), 359-385. https://doi.org/10.1080/14678802.2012.724792

Nilsson, A. (2005). Reintegrating ex-combatants in post-conflict societies. Estocolmo, Suecia: Swedish International Development Cooperation Agency.

ONU -Organización de las Naciones Unidas-. (1999). Disarmament, Demobilization and Reintegration of ExCombatants in a Peacekeeping Environment. Principles and Guidelines. Report of the Department of Peacekeeping Operations, December. Nueva York, Estados Unidos: DPKO/Lessons Learned Unit.

Oppenheim, B. y Söderström, J. (2018). Citizens by Design? explaining Ex-Combatant Satisfaction with Reintegration Programming. The Journal of Development Studies, 54(1), 133-152. https://doi.or g/10.1080/00220388.2017.1288225

Özerdem, A. (2012). A re-conceptualisation of ex-combatant reintegration: 'social reintegration' approach. Conflict, Security y Development, 12(1), 51-73. https://doi.org/10.1080/14678802.2012.667661 
Giovanny Sandoval-Paucar • Alexandra Arango-Ospina •Patricia Rodríguez-Vélez • Millerlandy Santana-Oviedo

Podder, S. (2012). From Recruitment to Reintegration: Communities and Ex-combatants in PostConflict Liberia. International Peacekeeping, 19(2), 186-202. https://doi.org/10.1080/13533312.2012.6 65696

Porch, D. y Rasmussen, M. J. (2008). Demobilization of paramilitaries in Colombia: Transformation or transition? Studies in Conflict y Terrorism, 31(6), 520-540. https://doi.org/10.1080/10576100802064841

Rettberg, A. (2013). Peace is better business, and business makes better peace: The role of the private sector in Colombian peace processes. GIGA Working Papers No. 240. http://dx.doi.org/10.2139/ ssrn. 2356238

Theidon, K. y Betancourt, P. A. (2006). Transiciones conflictivas: combatientes desmovilizados en Colombia. Análisis político, 19(58), 92-111.

Torjesen, S. (2013). Towards a theory of ex-combatant reintegration. Stability: International Journal of Security and Development, 2(3). http://doi.org/10.5334/sta.cx

Velasco, M. P.(2006). Participación del sector empresarial en la reinserción: percepciones y oportunidades. Recuperado de https://www.files.ethz.ch/isn/152326/participacion.pdf

Watteville, N. (2001). Demobilization and Reintegration: Addressing Gender Issues. Recuperado de https://openknowledge.worldbank.org/handle/10986/9810 